\title{
Transporto sentimentos
}

Viviane Vallades da Silva ${ }^{1}$

I carry feelings

Llevo sentimientos 


\title{
Resumo
}

Neste artigo, descreverei o processo criativo da obra Transporto sentimentos, de minha autoria. Durante a descrição, farei passagens de pensamentos que refletem sobre a ação e percurso de meu corpo em diferentes paisagens. Discorrerei sobre possibilidades de ação na paisagem da cidade através da prática artística, ruídos que uma ação pode causar assim como as indagações sobre tal ato.

\section{Palavras-chave: Corpo; Paisagem; Caminhar; Ação performática.}

\begin{abstract}
In this article I will describe the creative process of the work Transporto sentimentos [/ carry fellings] of my own. During the description I will make passages of thoughts that reflect on the action and course of my body in different landscapes. I will try to discuss through artistic practice possibilities of action in the city landscape, noises that an action can cause as well as questions about such an act.
\end{abstract}

Key-words: Body; Landscape; Walking; Performance action.

\section{Resumen}

En este artículo describiré el proceso creativo de la obra Transporto sentimentos [Llevo sentimientos]. Durante la descripción haré pasajes de pensamientos que reflexionen sobre la acción y el curso de mi cuerpo en diferentes paisajes. Trataré de discutir a través de la práctica artística las posibilidades de acción en el paisaje de la ciudad, los ruidos que una acción puede causar y las preguntas sobre tal acto.

Palabras-clave: : Cuerpo; Paisaje; Marcha; Actuación, acción.

\footnotetext{
${ }^{1}$ Artista e pesquisadora. Doutora em Artes Visuais pela Universidade de São Paulo, em 2019. Mestra em Ciências no Programa: Meios e processos audiovisuais pela mesma instituição em 2014. Bacharel em Artes plásticas pela UNESP em 2006. Link para Lattes: http://lattes.cnpq.br/2456352687629784. ORCID: https://orcid.org/0000-0002-3964-2276 email: vivianevallades@gmail.com
} 


\section{Introdução}

Pesquiso e realizo trabalhos em meios híbridos, seja em vídeo e performance, videoinstalação, pintura e performance etc. Na maioria de meus experimentos, utilizo meu corpo e também imagens desse realizando ações e modificações, por meio de peles artificiais, máscaras e pelo acréscimo de dispositivos, produzindo sensações visuais, táteis, auditivas, espaciais e temporais que buscam gerar reflexões sobre os corpos e a potência dos seres em geral. Através das ações que meu corpo realiza ou, em alguns outros trabalhos, por meio de palavras que remetem ao corpo e a seus comportamentos, pretendo produzir sensações e ficções que discutam questões ligadas à existência cotidiana como: relações sociais, efemeridade, mudanças de sensibilidade, subjetividade, relação humano-máquina e mecanização dos sentimentos.

São corpos de passagem que apresentam diferentes estados psicológicos e estados provisórios (lúdicos, criativos, resistentes, efêmeros etc.) do ser.

Muitos dos trabalhos que apresento abordam sentimentos, dúvidas e comportamentos dos corpos, sem querer aproximação com nenhum tipo de verdade. São apenas reflexões e principalmente ficções.

Em Transporto sentimentos realizei uma ação performática na qual conduzi um carrinho de mão dentro de alguns ônibus, pelas ruas do centro e de alguns bairros da cidade de São Paulo, e por uma praia no Guarujá. O carrinho continha uma caixa grande com a inscrição "Transporto sentimentos", telefone para contato com WhatsApp e e-mail. Vestida com um uniforme contendo as mesmas informações da caixa, segui pelos espaços até ser parada por algum transeunte que se interessasse ou questionasse a ação, para logo em seguida retomar a caminhada.

\section{Processo e desenvolvimento da obra}

O conceito da obra Transporto sentimentos surgiu por volta do final de 2015 . Eu estava realizando por essa época o trabalho Sem título, um work in process composto por frases inseridas no meu perfil pessoal do Facebook. As frases procuravam travar um diálogo com o espectador, por fazerem o uso de pronomes como você, teu e tua em seu conteúdo e por estarem abertas a todos que venham a se deparar com elas e lê-las durante o passeio pelas atualizações sociais de seus amigos do Facebook. O trabalho procurava trazer pelo estranhamento reflexões sobre as relações sociais, interpessoais, modos e posturas de existência.

Faço menção a essa obra porque foi a primeira em que passei a usar palavras/ frases em meus trabalhos. Creio que Transporto sentimentos seja uma extensão desse processo e procedimento artístico, tanto pelo uso de palavras como pela inserção do trabalho em âmbito social. $O$ trabalho das frases se inseria no contexto social do Facebook de forma pública e Transporto sentimentos, como comentado anteriormente e que detalharei mais a frente, o faz no espaço público: pelas ruas da cidade e pela praia. Esta foi a primeira ação artística que fiz corporalmente no âmbito do espaço público.

Nessa época, eu cursava uma disciplina no MAC-USP e, uma vez, quando atra- 
vessava a passarela Ciccilo Matarazzo, para ir do Ibirapuera ao MAC, vi um homem carregando diversas caixas que, pela quantidade, impossibilitavam a visão de seu corpo inteiro. Não sei ao certo o que ele carregava, mas eram caixas de papelão. Ele passou e fiquei parada na passarela pensando e tive a ideia de carregar caixas que lembrassem caixas de transporte de obras de arte (mais comuns para quadros, esculturas etc.) e adicionar inscrições nelas. Como estava com o pensamento voltado à realização de frases que trabalhassem questões existenciais cotidianas, logo surgiu a vontade de escrever "Transporto sentimentos". Continuei meu trajeto com esse pensamento na cabeça.

Um ou dois meses após esse insight (que era realizar a ação de carregar um carrinho de mão com uma caixa com a inscrição "Transporto sentimentos" por vários pontos da cidade de São Paulo e também por uma praia), fui viajar e passar o fim de ano na praia, em São Sebastião. Lá realizei, com ajuda de Marcos Nobre e Regina Vallades, alguns esboços com vídeos e fotos de como seria fazer esse trabalho na praia e pelas ruas ao redor, pois a ideia de fazê-lo na cidade e nas praias já estava nítida. Tirei fotos e fiz vídeos curtos e aproveitei um carrinho de praia para simular o carrinho de mão que usei na obra final.
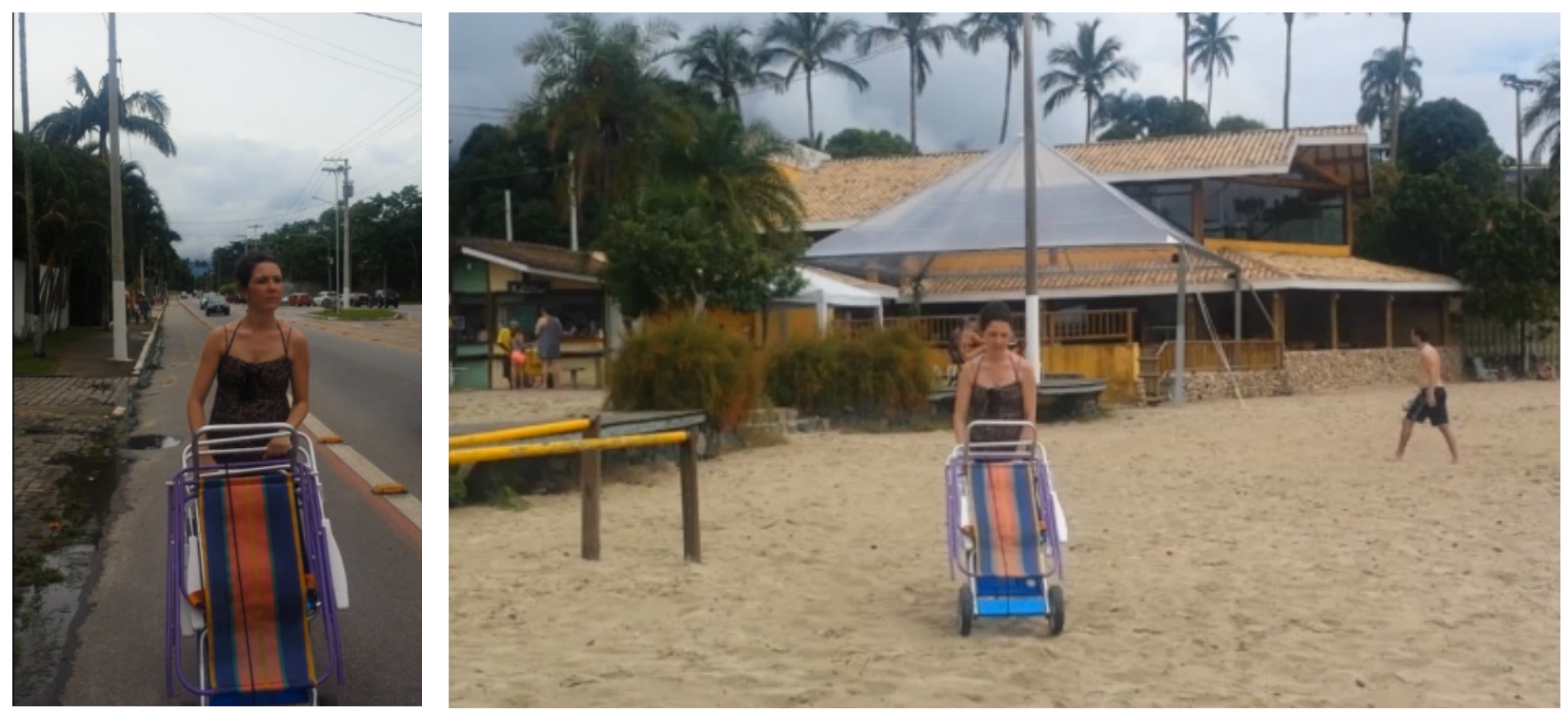

Fig. 1 e 2: Testes para o trabalho Transporto sentimentos, 2016.

Fiz um vídeo curto com um carrinho semelhante ao que pretendia utilizar e caminhei, saindo e entrando do enquadramento do vídeo, como nas fotos anteriores (figs. 1 e 2). Planejei essa ação na qual saía e entrava do quadro porque pretendia realizar uma videoinstalação com três telas em que o sair e o entrar em cena estabelecessem uma relação de continuidade, de movimento entre as projeções, conectando espaços diferentes. Assim, em uma das telas eu estaria na praia e sairia de enquadramento para que na tela ao lado estivesse entrando em outro espaço (por exemplo, numa rua da cidade de São Paulo).

Posteriormente, quando voltei da praia para São Paulo, retomei esse material e fiz algumas edições de entrada e saída de quadro e entendi como poderia fazer a edição desse trabalho. 
Com esse material em mãos, li que estava aberto o edital de 2016 do LABMIS (Laboratório de Novas Mídias do Museu da Imagem e do Som em São Paulo) e resolvi me inscrever com Transporto sentimentos. O material enviado foi o que tinha feito como esboço na praia e mais algumas fotos de imagens de carrinho de mão, juntamente com modelos de uniformes (roupas) para usar durante a ação.

Tinha em mente que usaria uma roupa específica, que utilizaria caixas semelhantes às de transporte de obras de arte (já que estava fazendo arte, a caixa simbolizaria o transporte de sentimentos no âmbito das artes) e que faria uma videoinstalação com três projeções de vídeos lado a lado. Também havia no projeto a informação de que eu adicionaria um número de telefone com WhatsApp e e-mail nas caixas, juntamente com a inscrição de "Transporto sentimentos".

O projeto de Transporto sentimentos foi selecionado e passei a fazer mais esboços: para tamanho das caixas e quantidade delas, tamanho da letra das inscrições nelas contidas, cor do uniforme e número do telefone que usaria. Comprei um chip apenas para o trabalho de modo a facilitar a distinção entre as mensagens enviadas para o trabalho e minhas mensagens pessoais.

Com a expansão das formas de comunicação que propus para além do contato direto na rua durante a ação, através de e-mail e número de telefone com WhatsApp na caixa, abri possibilidades para uma comunicação posterior com os que se interessassem no serviço e quisessem entrar em contato comigo. Poderia assim dar continuidade ao trabalho via telefone, WhatsApp ou por e-mail. Confeccionei também cartões com as mesmas informações contidas na caixa sobre o oferecimento do serviço.

A Residência Artística no LABMIS teve duração de três meses (de maio a julho de 2016). Após escolher todos os elementos do trabalho, confeccionei também um uniforme sob medida - um macacão cinza (neutro) que na parte posterior apresentava as mesmas informações contidas na caixa de modo a ficar visível o serviço quando estivesse de costas. Fiz essa escolha pois um uniforme nos moldes sociais gera mais segurança, comprometimento e autenticidade ao trabalho. Contactei o Kadu Rossi, técnico de filmagem que me acompanhou durante toda a ação. Poderia convidar um amigo que soubesse filmar, porém, a escolha de trabalhar com desconhecidos também fez parte do processo, já que meus trabalhos procuram tecer fios nas tramas das relações sociais, convivência e acasos dessas relações. 

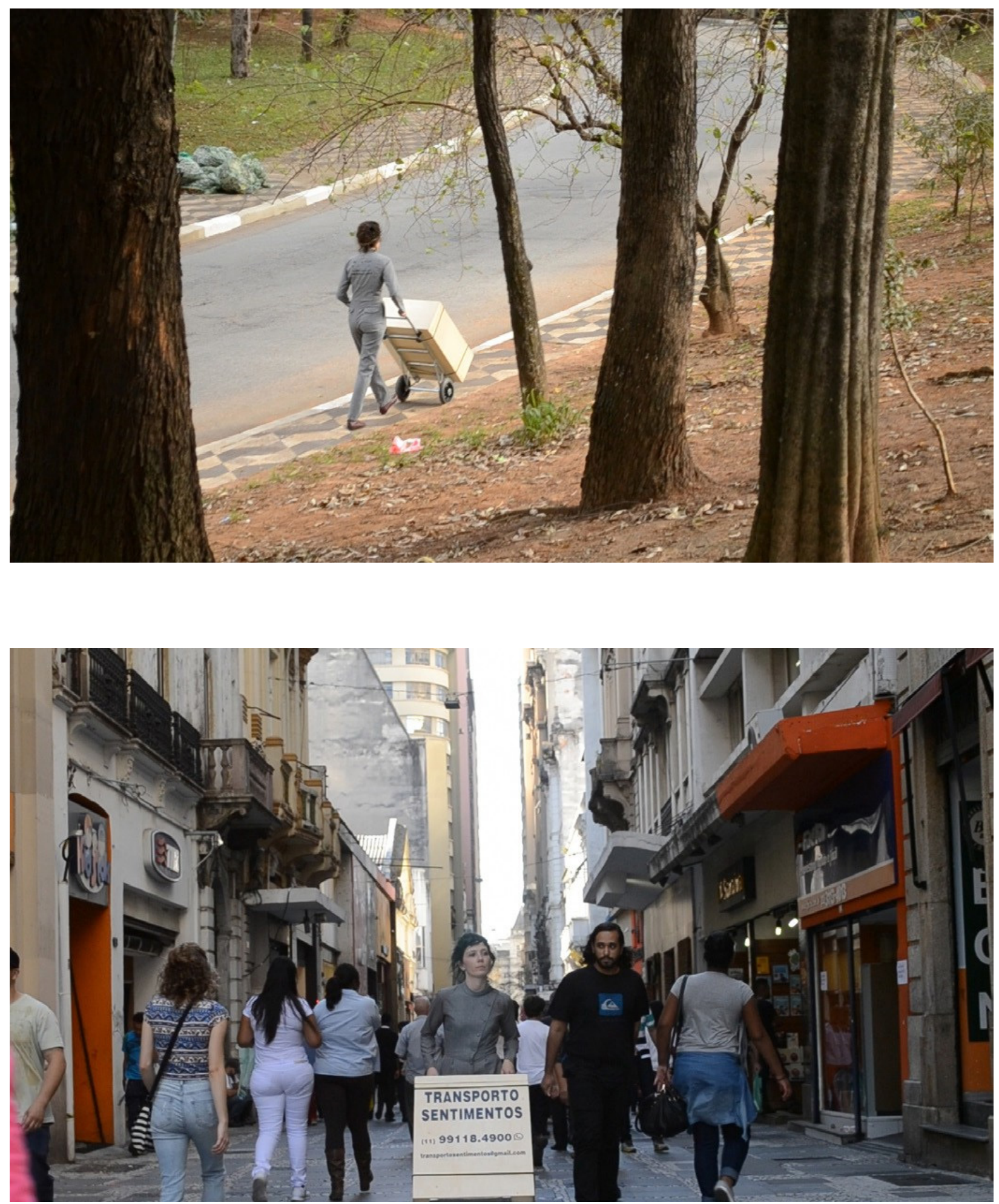

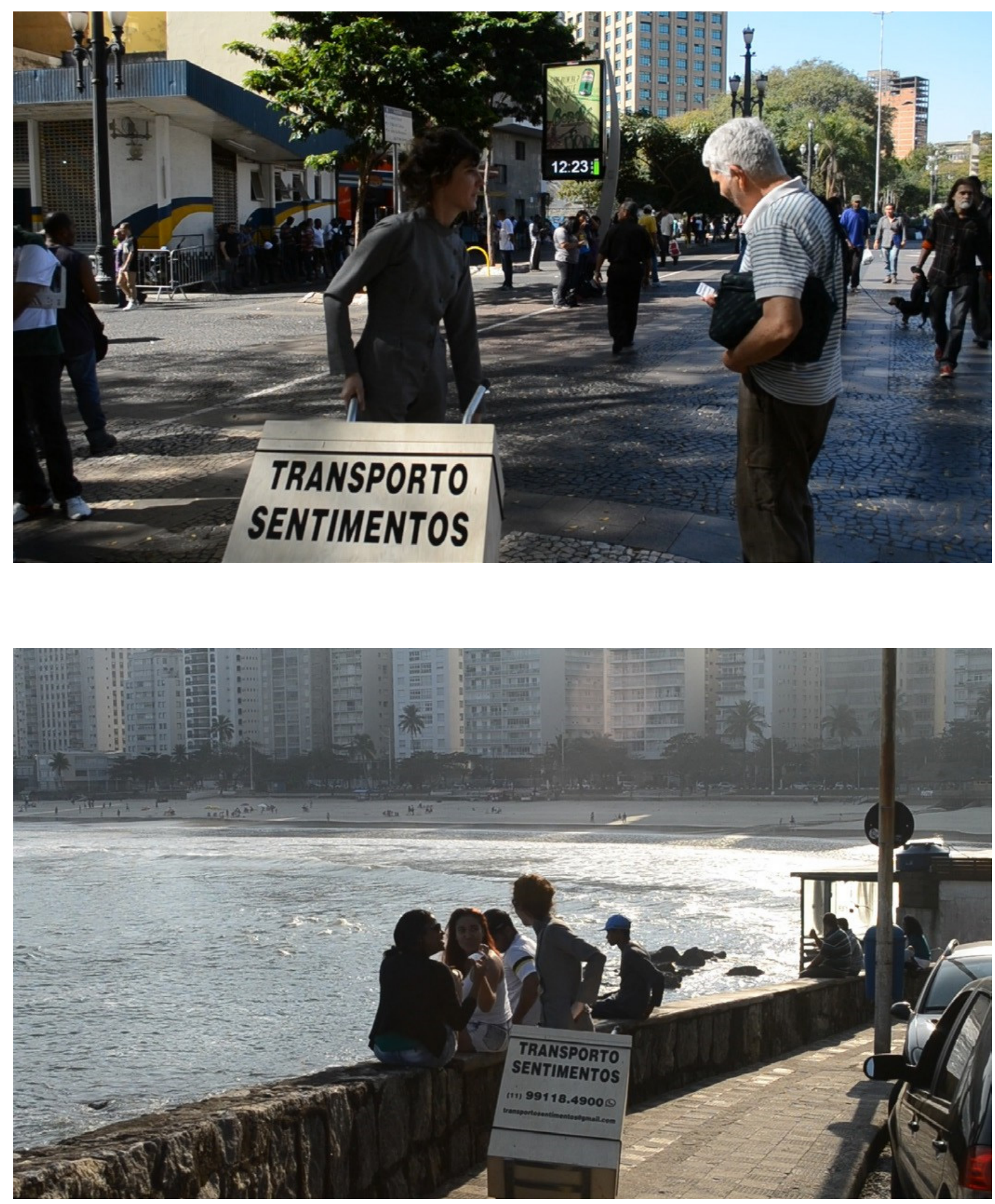

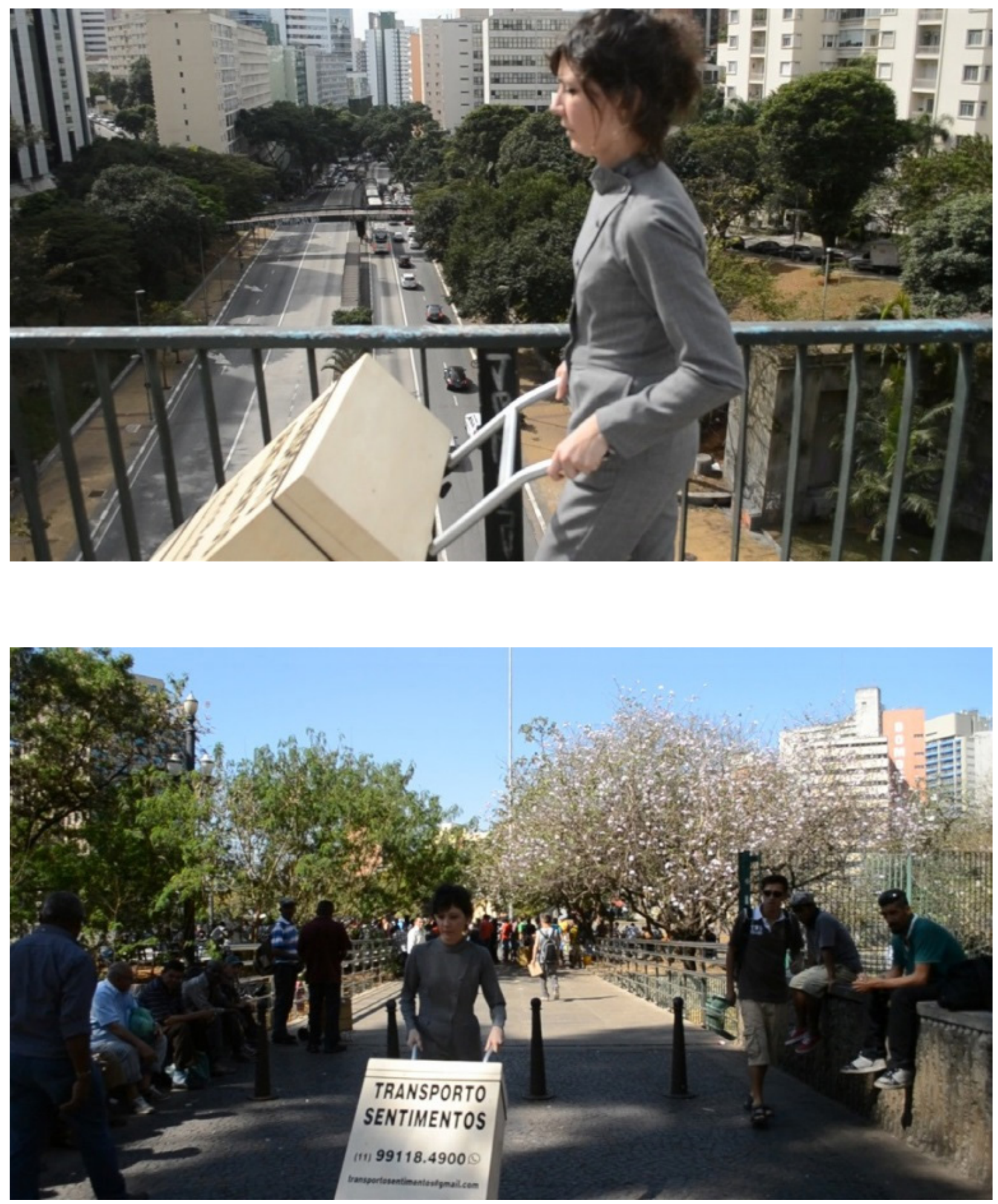

Fig. 3 a 8: Frames da videoinstalação Transporto sentimentos, 2016. Câmera: Kadu Rossi. 


\section{TRANSPORTO SENTIMENTOS (11) $99118-4900$ ๑ transportosentimentos@gmail.com}

Fig. 9: Cartão distribuído durante a ação para os transeuntes que se interessassem pelo serviço.

Após os dias da ação e de captação das imagens, iniciei o trabalho de edição dos vídeos para tripla projeção.

Em alguns momentos da videoinstalação encontram-se frames pretos em algumas das telas, ficando ora um vídeo projetado, ora dois, ora três vídeos projetados simultaneamente.

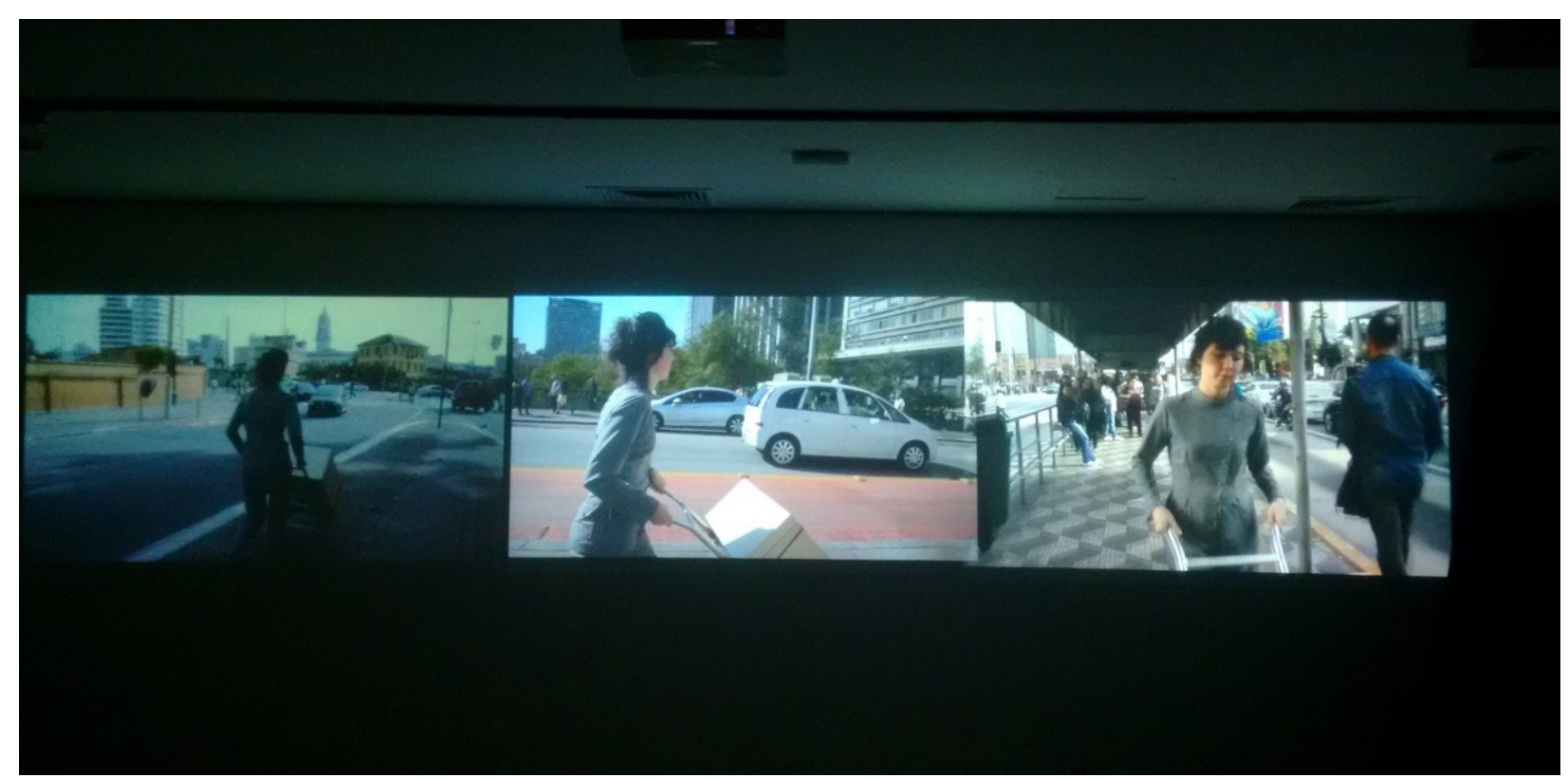

Fig. 10: Exposição no MIS, em SP em 2017. 
Charlatanismo, ritual, isca para uma interação social, um ruído estranho no cotidiano, mesclar-se como mais uma ambulante na cidade, acaso, possibilidade futura através da tecnologia, uma ação dentro da vida? São proposições e questões que esse trabalho suscita. E como resposta ele perpassa todos esses itens.

Meus interesses em produzir essa ação eram diversos. Ao mesmo tempo que me propus de fato transportar sentimentos simbolicamente, a começar pelos meus, também me interessavam todas as questões que pudessem ser levantadas sobre a ação, que já existiam como possibilidades antes mesmo de começá-la e que de fato foram suscitadas pelas pessoas, como, por exemplo, a desconfiança sobre o serviço. Gerar questionamentos sobre sua autenticidade ao observar algo que é prometido era também um dos interesses nesse trabalho. Hoje, diversos produtos e serviços são oferecidos a todos nós sem passar muito por nossa reflexão. Tudo é produto, tudo é comercializado. E foi um pouco isso que tive intenção de provocar.

Gerar interações, conversas sobre histórias e desejos também faziam parte das minhas intenções. Outro ponto forte do conceito da obra era causar um ruído, um estranhamento no cotidiano. Observar carrinhos que vendem Yakult, pipoca e outros produtos nas cidades, e até mesmo na praia, é comum, porém causei um ruído/ estranhamento por fazer uso da inscrição "Transporto sentimentos", ainda mais por estender esse transporte como um serviço oferecido ao outro.

Estando mesclada aos vendedores pela cidade ou pela praia, apropriando-me dos moldes sociais de um vendedor cotidiano, eu estava trabalhando e abordando também o seguinte questionamento: em pouco tempo, será possível através da tecnologia transportar sentimentos através de modificações de memória ou processos similares, por exemplo? Esse fato modificará nossos sentimentos, nossos modos de sentir e existir?

Hoje, muitas alterações que podem parecer absurdas podem logo se tornar cotidianas. A memória é um exemplo disso. Paula Sibilia, em seu livro O show do eu: a intimidade como espetáculo (2008), apresenta estudos e possíveis conclusões desenvolvidos por equipes das Universidades Harvard e McGill sobre as possibilidades de apagamento ou criação de memórias através de remédios.

Nossas recordações seriam plásticas e, portanto, potencialmente moldáveis - ou seja, tecnicamente manipuláveis. Pode até soar paradoxal, mas seriam justamente aquelas lembranças que se encontram mais profundamente assentadas, aquelas instaladas há muito tempo ou de forma mais intensa em nossas mentes, as que poderiam ser apagadas. (SIBILIA, 2008, p. 127)

Com essa descoberta, feita pela equipe das Universidades Harvard e McGill, de que o cérebro lida diferentemente com lembranças comuns e rotineiras daquelas carregadas de emoção, os pesquisadores chegaram à conclusão de que as recordações mais fortes e emotivas podem ser flexíveis sob condições emocionais. A partir dessa descoberta e do funcionamento dos mecanismos cerebrais, medicamentos que inibem os efeitos biológicos na formação dessas lembranças mais fortes - como a substância propranolol - poderiam apagar algumas memórias. $O$ medicamento seria usado assim que a lembrança ocorresse. 
A partir das possibilidades de modificação do funcionamento cerebral - cuja aplicação pode não estar tão distante assim -, as mudanças corporais através da tecnologia genética, dentre outros exemplos, muitos artistas abordam a dicotomia natural/ artificial, assim como as alterações de nossas vidas por meio da tecnologia. Alguns, por exemplo, operam pela ficção ou no campo entre o real e a ficção através da mistura de notícias divulgadas mais recentemente juntamente com as novas possibilidades tecnológicas. Nessa linha trabalha o artista norte-americano Virgil Wong, que apresenta notícias fictícias que misturam genética, notícias recentes e novas possibilidades corporais através da tecnologia em seu site, RYK Hospital. No site, ele disponibiliza, por exemplo, fotos, textos e um breve documentário, The World's First Male Pregnancy (elaborado por ele e por Lee Mingwei,), que traz informações sobre a primeira gravidez masculina (NUNES, 2016, p. 90). Os artistas, inspirando-se no modelo de documentário e seguindo os parâmetros desse gênero, vão explicando no documentário como isso aconteceu e suas implicações sociais, bem como o que isso alteraria em termos de relações sociais e modos de existir.

Muitos artistas também optam por um direcionamento reflexivo e criativo sobre veracidade/ ficção nas mídias sociais, como a apresentação de personas. Em seu livro Mentira de artista: arte (e tecnologia) que nos engana para repensarmos o mundo (2016), Fábio Oliveira Nunes (artista, professor e pesquisador brasileiro) aponta a "mentira" como "método criativo", como estratégia de criação. Ele estuda e conceitua a mentira de artista através de trabalhos que se passam pelo que não são. Ele aponta que iludir no campo da arte não é uma metodologia nova, como as pinturas miméticas que enganam pela semelhança em ser o que não são. Na arte contemporânea, essa estratégia metodológica é continuada com os anseios da época. Mas trata-se de uma mentira de natureza poética, uma incursão estratégica que leva em conta o contexto como um sistema em que atua. Essas mentiras de artistas são como organismos que se passam por outros. Semelhantemente ao que ocorre na natureza com os animais que fingem ser o que não são dentro de um contexto.

Seria o que o autor chama de mimetismo sistêmico, isto é, assim como acontece na natureza, as proposições artísticas mesclam-se com o ambiente, com o espaço, com o contexto e criam inter-relações.

O mimetismo e "a mentira" de parecer ser o que não se é são estratégias utilizadas nas proposições artísticas não apenas para um efeito de trote ou piada (embora também tenham esse teor), mas principalmente para dialogar "com mundo de aparências, expectativas e superficialidade, e, tal como a ficção científica, criam modelos capazes de repensar contextos nos quais trafegamos". (NUNES, 2016, p. 21)

Transporto sentimentos abordou esse procedimento artístico de se mesclar ao ambiente social, ao contexto em que foi inserido e chamou muita atenção tanto pelo texto escrito, mas também pela parte sonora, pois as rodas do carrinho faziam muito barulho durante o movimento de caminhar, colaborando para atrair mais atenção. $O$ fato de eu ser uma mulher a carregar um carrinho com uma caixa um tanto grande pode também ter sido um outro componente de atração para a ação. Portanto, mesclei-me à paisagem cotidiana, causando porém um estranhamento, reflexões com a ação. 
Em todos os espaços por onde passei, a grande maioria das pessoas observou a ação e percebeu que se tratava de algo estranho. Em nenhum momento passei despercebida. Algumas contribuições ou participações dos espectadores no trabalho se deram por trocas e conversas lúdicas, chacotas, críticas ou manifestações de descrédito. Outras pessoas desejavam mesmo transportar seus sentimentos.

O encontro com o outro, com o inesperado, com as possíveis reações que aconteceriam me causavam medo, alegria, curiosidade etc. A ação seria um experimento para o outro e para mim também. Afinal, estava trabalhando minhas percepções e possíveis respostas diante do que viria, tanto física quanto emocionalmente - como, por exemplo, me observar diante de questões, dúvidas, chacotas etc.

Eu estava em local público e cada vez que saía com o carrinho buscava o encontro, me expor ao outro, experienciar uma situação inusitada, observar-me, observar a cidade, seus acessos, observar os transeuntes, suas falas, suas reações, ao mesmo tempo que minha concentração era bem intensa durante o ato de conduzir o carrinho.

Nessa obra, trabalhei na esfera social em dois espaços: o da exposição (a mostra no MIS) e do urbano/público onde foi realizada a ação. Assim, lidei com o interstício social de que fala Bourriaud em relação às formas de operar o intercâmbio humano na arte contemporânea, diferentes das zonas de comunicação que nos são impostas. Segundo o autor:

(...) para nós, além de seu caráter comercial ou de seu valor semântico, a obra de arte representa um interstício social. O termo interstício foi usado por Karl Marx para designar comunidades de troca que escapavam ao quadro da economia capitalista, pois não obedeciam à lei do lucro: escambo, vendas com prejuízo, produções autárquicas etc. O interstício é um espaço de relações humanas que, mesmo inserido de maneira mais ou menos aberta e harmoniosa no sistema global, sugere outras possibilidades de troca além das vigentes nesse sistema. (BOURRIAUD, 2009, p. 22-23).

Com esse trabalho, criei um espaço para troca, para relação social através de conversas, de possíveis "encomendas" e, embora me utilize de "tipos de comunicações" tradicionais da vida cotidiana e também muito utilizadas no comércio como o telefone, o WhatsApp e o e-mail, o serviço que ofereço é de troca. Não há taxa para sua realização, estando portanto, mesmo que valendo-se dos padrões formais do comércio, fora do sistema comercial e financeiro tradicional. Pela sua analogia a trabalhos nos moldes comerciais, muitas pessoas me perguntaram quanto eu cobrava pelo serviço. Nesse sentido, durante meu trajeto no metrô foi necessário esconder com um plástico as informações de telefone, e-mail e os dizeres da caixa, pois ali entendiam esse trabalho com finalidades comerciais, não podendo assim circular no metrô. Fazer propaganda no metrô é proibido, a não ser que se pague por isso.

Esse trabalho também tem ligação com algumas práticas contemporâneas, como $o$ ato de caminhar e de realizar ações em espaços fora dos espaços tradicionais de arte, como a cidade. Careri (2013, p. 27), na introdução de seu livro Walkspaces: o caminhar como prática estética, dispõe em três colunas várias palavras que podem ser enlaçadas à vontade para se criar, ler e realizar ações. Algumas das palavras que o 
autor cita são: habitar, percorrer, caminhar, perder-se, errar, pessoas, sensações, uma cidade etc. Acrescento: transportar, sentimentos, passagens de estado.

Essas palavras, segundo o autor, são ações que entraram mais recentemente para a história da arte "e que podem revelar-se um útil instrumento estético com o qual explorar e transformar os espaços nômades" (CARERI, 2013, p. 27). Nesse livro, o autor trata do caminhar de modo geral, mas foca em demonstrar que o caminhar tem produzido arquitetura e paisagem. O autor inicia sua reflexão com os caçadores do paleolítico, passando pelas práticas dadaístas, dos surrealistas, assim como dos situacionistas e da Land Art, dentre outros. O estudo é significativo por abordar uma genealogia do caminhar, assim como também os movimentos e artistas que fizeram esse uso. Práticas consideradas performáticas e com o ato de caminhar em seu foco foram realizadas pelos dadaístas desde o início do século XX. Embora não tenham de fato realizado muitas experimentações na cidade, eles deram novas possibilidades de agir nela.

No trabalho que realizei, além de sua inserção e genealogia no campo da prática artística contemporânea ligada principalmente ao caminhar na cidade e às passagens de estados psíquicos que propõe, também pretende entender o caminhar como filosofia. Quando tive o desejo de realizar esse trabalho, que teve como insight a imagem de um rapaz, um carregador de caixas de papelão andando pela passarela da avenida 23 de Maio, pensei em realizar uma ação de caminhar, carregar, talvez por remeter mais fortemente à ideia de transporte.

O caminhar foi prática filosófica realizada por muitos pensadores, artistas, poetas como forma de buscar mudanças de estados emocionais, como fonte de encontro de ideias, pensamentos, criações, como fuga, para livrar-se de depressões. Por que não para transportar sentimentos?

\section{Considerações finais}

Realizar o trabalho em espaço público foi muito interessante por ampliar as possibilidades de interação, de trocas e por vivenciar a situação que o trabalho estava causando in loco. Oferecer também uma possível continuidade do trabalho através de contato de telefone, Whatsapp e e-mail foi também um diferencial, pois realmente quem pedia ou a quem eu oferecia o cartão de contato com o oferecimento do serviço após uma conversa presencial acabava me escrevendo ou me telefonando. Dessa forma, a interação com o trabalho foi estendida. Apresentá-lo em espaço expositivo também trouxe outra forma para a obra, pois o formato de videoinstalação de projeção dos vídeos em três projeções lado a lado tomou uma forma diferente de leitura em relação a ação nas ruas. No espaço expositivo a leitura das projeções gerava continuidades da ação em diferentes paisagens.

Pretendo dar continuidade a esse trabalho, realizando-o em outros estados e países de forma a observar como ele é recebido em diferentes culturas e costumes. Pretendo também realizar, após a captação das imagens de estados e países diferentes, uma videoinstalação com mais telas e estender a ação de transportar sentimentos de um canto a outro do mundo. 


\section{Referências}

BAUMAN, Zygmunt. Vida para consumo: a transformação das pessoas em mercadoria. Trad. Carlos Alberto Medeiros. Rio de Janeiro: Jorge Zahar Ed., 2008.

BOURRIAUD, Nicolas. Estética relacional. Trad. de Denise Bottmann. São Paulo: Martins Fontes, 2009. (Coleção "Todas as Artes")

Pós-Produção: como a arte reprograma o mundo contemporâneo. Trad. de Denise Bottmann. São Paulo: Martins Fontes, 2009. (Coleção "Todas as Artes")

CARERI, Francesco. Walkscapes: o caminhar como prática estética. Trad. Frederico Bonaldo. São Paulo: Editora G. Gili, 2013.

GROZ, Frédéric. Caminhar, uma filosofia. Trad. Lília Ledon da Silva. São Paulo: É Realizações Editora, 2010.

NUNES, Fábio Oliveira. Mentira de artista: arte (e tecnologia) que nos engana para repensarmos o mundo. São Paulo: Cosmogonias Elétricas, 2016.

RUSH, Michael. Novas mídias na arte contemporânea. Trad. Cássia Maria Nasser. São Paulo: Martins Fontes, 2006.

SIBILIA, Paula. O show do eu: a intimidade como espetáculo. Rio de Janeiro: Nova Fronteira, 2008.

O homem pós-orgânico: corpo, subjetividade e tecnologias digitais. 3.ed.

Rio de Janeiro: Relume Dumará, 2006.

Submetido em: 30/10/2019

Aceito em: 18/03/2020 